\title{
Mechanical Properties of High-Performance Lightweight Aggregate Concrete with Inorganic Polymers Cement Based on Multiple Minerals under Uniaxial Loading
}

\author{
Xiao Ma and Qiuhua Rao \\ School of Civil Engineering and Architecture, Central South University, Changsha 410075, China \\ Correspondence should be addressed to Qiuhua Rao, raoqh@csu.edu.cn
}

Received 18 November 2011; Revised 29 February 2012; Accepted 7 March 2012

Academic Editor: Jin Ping Lu

Copyright () 2012 X. Ma and Q. Rao. This is an open access article distributed under the Creative Commons Attribution License, which permits unrestricted use, distribution, and reproduction in any medium, provided the original work is properly cited.

\begin{abstract}
High-performance lightweight aggregate concrete with inorganic polymers cement based on multiple minerals is a very promising new material. The research of mechanical properties of the new material is of great theoretical and practical significance. In this research, the failure behavior, cubic and prism compressive strength, elastic modulus, peak strain of the new material, and the nature of the stress-strain curve are studied. An analytical model is quoted to represent the ascending and descending parts of the stress-strain curve.
\end{abstract}

\section{Introduction}

The use of lightweight aggregate concrete has many advantages including dead load reduction, high thermal insulation, and enhanced fire resistance [1]. The principal hydraulic binder of the lightweight aggregate concrete adopted was typically Ordinary Portland Cement (OPC). However, OPC was not an environment-friendly product and also has many disadvantages, for example, it is not only energy intensive, but is also responsible for large emissions of carbon dioxide $\left(\mathrm{CO}_{2}\right)$-a greenhouse gas [2]. Inorganic polymer cement is a new class of green ecological cementitious materials which has better performance than OPC, including good mechanical properties, chemical resistance and temperature resistance, rapid setting property, low-energy consumption, and greenhouse emissions [3-5]. It has been attracting more and more attention of materials researchers in recent years [6-8]. High-performance lightweight aggregate concrete with inorganic polymers based on multiple mineralss has the advantages of light weight, high strength, high-dimensional stability, excellent durability, and good workability. Obviously, combination of inorganic polymer with lightweight aggregate concrete can reduce alkali aggregate reaction effectively and exhibit lower hydration heat, excellent corrosion resistance, good permeability, and frost resistance comparing with the OPC $[9,10]$. There is few literature works reported on this new material.

The aim of this paper is to study the mechanical properties of the new high-performance lightweight aggregate concrete, in order to provide basic data for application of this new material in engineering.

\section{Experimental Details}

2.1. Materials. The multiple minerals used in this test was slag mixed with metakaolin and fly ash (wt. ratio: slag powder/metakaolin $=8$, slag powder/fly ash $=8$ ). Slag powder has mean particle size of $19.35 \mu \mathrm{m}$ and Blaine fineness of $2700 \mathrm{~cm} 2 / \mathrm{g}$. Metakaolin was produced by calcination of kaolin at $750 \circ \mathrm{C}$ in rotary kiln. Fly ash was type I fly ash according to GB/T1596-2005. Table 1 lists main chemical compositions of the three minerals. The activators selected were liquid sodium silicate (wt. ratio: $\% \mathrm{Na}_{2} \mathrm{O}=8.26, \%$ $\mathrm{SiO}_{2}=26.12 ; \%$ water $=65.62$; industrial grade) blended with sodium hydroxide solution ( $30 \% \mathrm{w} / \mathrm{v}$ water solution).

The fine aggregate was river sand, with a specific gravity of 2.66 and a fineness modulus of 2.75. The coarse aggregate was a synthetic lightweight aggregate made from expanded shale, with particle density of $1550 \mathrm{~kg} / \mathrm{m}^{3}$, bulk density of $620 \mathrm{~kg} / \mathrm{m}^{3}$, and particle size ranging from 5 to $15 \mathrm{~mm}$. Its 
TABLE 1: Chemical compositions of materials.

\begin{tabular}{lccccccrrr}
\hline & $\mathrm{SiO}_{2}$ & $\mathrm{Al}_{2} \mathrm{O}_{3}$ & $\mathrm{CaO}$ & $\mathrm{Fe}_{3} \mathrm{O}_{4}$ & $\mathrm{MgO}$ & $\mathrm{Na}_{2} \mathrm{O}$ & $\mathrm{K}_{2} \mathrm{O}$ & $\mathrm{SO}_{3}$ & $\mathrm{Loss}$ \\
\hline Slag powder & 33.19 & 16.45 & 35.39 & 1.26 & 8.07 & 0.34 & 0.36 & 2.36 & 1.02 \\
Metakaolin & 51.28 & 42.39 & 0.31 & 1.74 & 0.27 & 0.15 & 0.22 & 1.12 \\
Fly ash & 53.36 & 25.52 & 4.63 & 7.86 & 1.10 & 0.92 & 1.35 & 0.44 & 2.52 \\
\hline
\end{tabular}

TABLE 2: Mix proportions of the lightweight aggregate concretes with inorganic polymer.

\begin{tabular}{lcccc}
\hline No. & $\begin{array}{l}\text { Liquid/multiple minerals } \\
\text { (mass ratio })\end{array}$ & $\begin{array}{l}\text { Sand/multiple minerals (mass } \\
\text { ratio) }\end{array}$ & $\begin{array}{l}\text { Liquid sodium silicate/sodium } \\
\text { hydroxide solution (mass ratio) }\end{array}$ & $\begin{array}{c}\text { Lightweight aggregate } \\
\text { volume fraction }(\%)\end{array}$ \\
\hline M & 0.45 & 0.9 & 0.9 & 0 \\
LAC1 & 0.45 & 0.9 & 0.9 \\
LAC2 & 0.45 & 0.9 & & 30 \\
& & & 0.9 \\
LAC3 & 0.45 & 0.9 & 50 \\
\hline
\end{tabular}

water absorption values were $3.5 \%$ and $4.5 \%$ at 1 hour and 24 hours, respectively, and crushing strength was $5.2 \mathrm{MPa}$.

2.2. Mix Proportions. Table 2 shows four specimens of lightweight aggregate concretes with inorganic polymer having the same composition of mortar matrix but different volume fractions of lightweight aggregate in concrete $(0,30 \%, 40 \%$, and $50 \%$ ).

2.3. Preparation of Specimens. Uniform lightweight aggregate concretes with inorganic polymer were prepared by drymixing the raw materials of lightweight aggregate concrete based on inorganic polymer for about $60 \mathrm{sec}$. adding the liquid activator and then mixing them for $90 \mathrm{~s}$. Three specimens of this materials in each group were cast in steel moulds and compacted on vibration table. The specimens have sizes of $100 \mathrm{~mm} \times 100 \mathrm{~mm} \times 100 \mathrm{~mm}$ in cube and $100 \mathrm{~mm} \times 100 \mathrm{~mm} \times 300 \mathrm{~mm}$ in prism for testing the cubic compressive strength and the stress-strain curves, repectively. After being kept in indoor environment for 24 hours, all the specimens were demolded and stored in the curing room $(20 \pm 3 \circ \mathrm{C}, 95 \%$ relative humidity) until testing at 28 days.

2.4. Test Setup and Method. Compression strength of cubic specimens and stress-strain curve of prism specimen were tested on a $2000 \mathrm{kN}$ hydraulic compression testing machine and an INSTRON 1346 electrohydraulic servouniversal testing machine, respectively. Figure 1 shows the test setup for the stress-strain curve. The strain rate was kept constant at $5 \times 10^{-5} \mathrm{sec}^{-1}$. Before testing, every prism specimen was preloaded and repeated three times at $30-40 \%$ of the estimated peak stress to reduce the error caused by the end effect of the specimens. The test results obtained were average values of three specimens in each group.

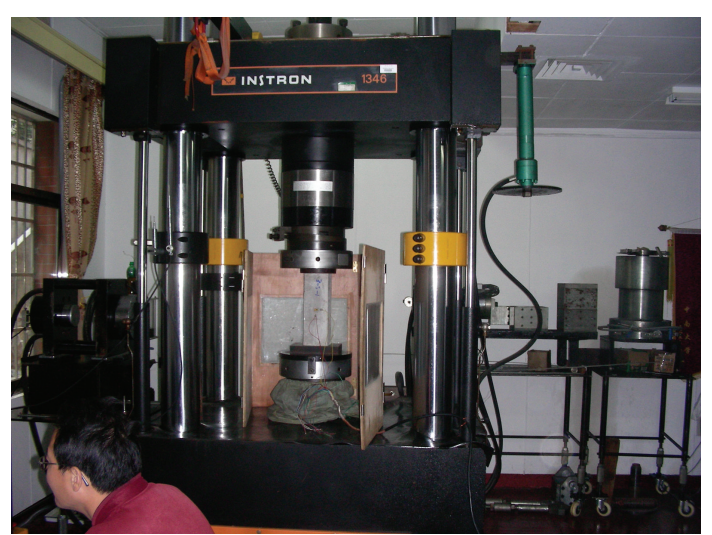

FIgURE 1: Test setup for the stress-strain curve.

\section{Results and Discussion}

3.1. Stress-Strain Curves. Figure 2 shows stress-strain curves of the concrete with different volume fractions of lightweight aggregate. There are four stages: compacting stage, elastic stage, plastic stage, and failure stage. Clearly, the lightweight aggregate volume fraction has great effect on mechanical properties of the aggregate concretes, the curvature of every ascending branch of the stress-strain curve decreased with an increase in lightweight aggregate content; this means that the elastic and ultimate strength of the concrete decreased as the lightweight aggregate volume fraction increased.

3.2. Compressive Strength. Table 3 lists cubic and prism compressive strengths of the lightweight aggregate concretes with inorganic polymer. It is seen that both the cubic $\left(f_{\mathrm{cu}}\right)$ and prism $\left(f_{c}\right)$ compressive strength of the concrete decreases as the lightweight aggregate volume fraction increases, due to 
TABLE 3: Cubic and prism compressive strength of lightweight aggregate concretes with inorganic polymer.

\begin{tabular}{|c|c|c|c|c|}
\hline No. & $\begin{array}{l}\text { Cubic compressive strength } \\
f_{\text {cu }}(\mathrm{MPa})\end{array}$ & $\begin{array}{l}\text { Prism compressive strength } \\
f_{c}(\mathrm{MPa})\end{array}$ & $f_{c} / f_{\mathrm{cu}}$ & Lightweight aggregate volume fraction (\%) \\
\hline M & 92.3 & 81.1 & 0.88 & 0 \\
\hline LAC1 & 62.6 & 56.6 & 0.90 & 30 \\
\hline LAC2 & 55.7 & 51.0 & 0.92 & 40 \\
\hline LAC3 & 48.2 & 45.8 & 0.95 & 50 \\
\hline
\end{tabular}

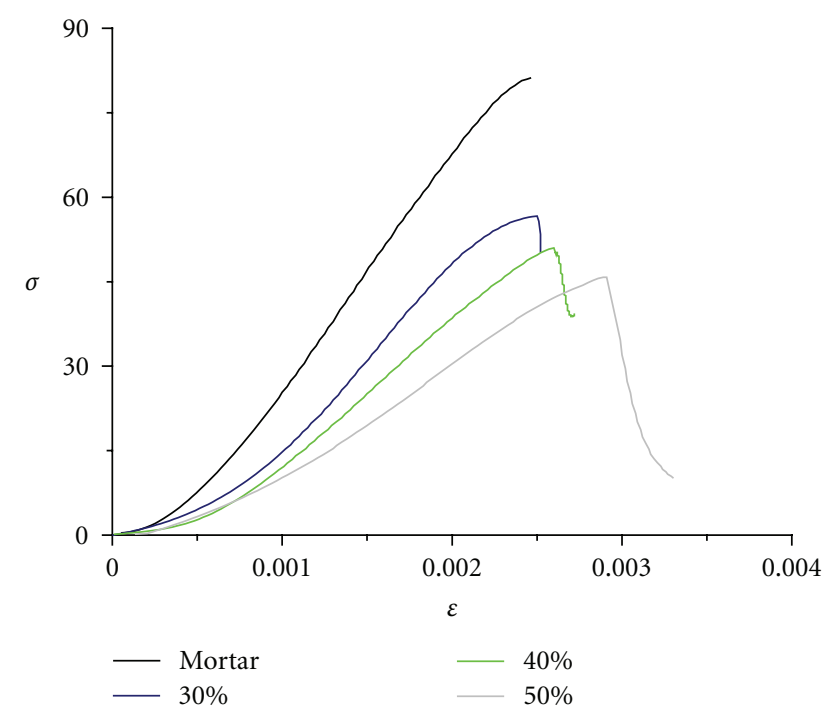

FIGURE 2: Stress-strain curves of concrete containing different volume fraction of lightweight aggregate.

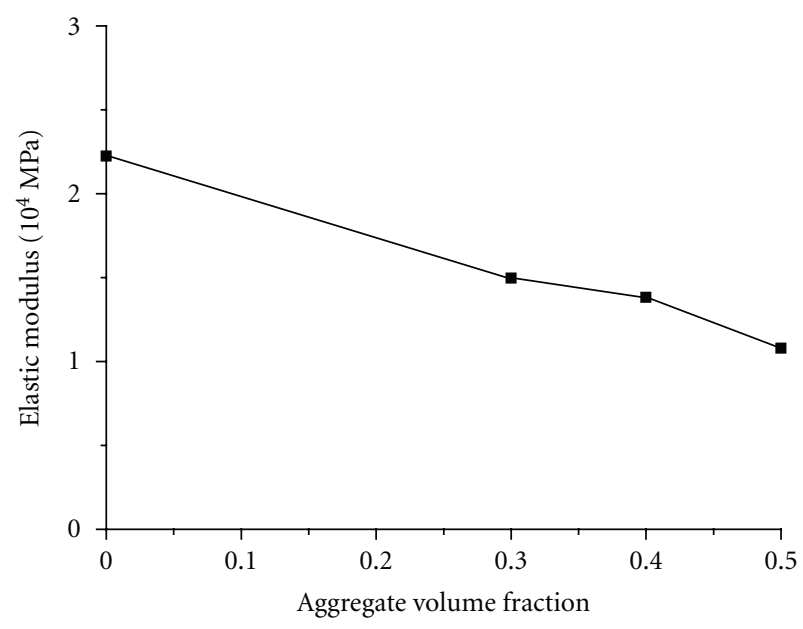

FIGURE 3: Elastic modulus of concretes with different volume fractions of lightweight aggregate.
TABle 4: The parameters $A, B$, and $C$ of the model.

\begin{tabular}{lccc}
\hline No. & $A$ & $B$ & $C$ \\
\hline LAC1 $(30 \%)$ & 0.3147 & 0.9975 & 901.0249 \\
LAC2 (40\%) & 0.3706 & 0.8262 & 231.6766 \\
LAC3 (50\%) & 0.4561 & 0.7339 & 325.7177 \\
\hline
\end{tabular}

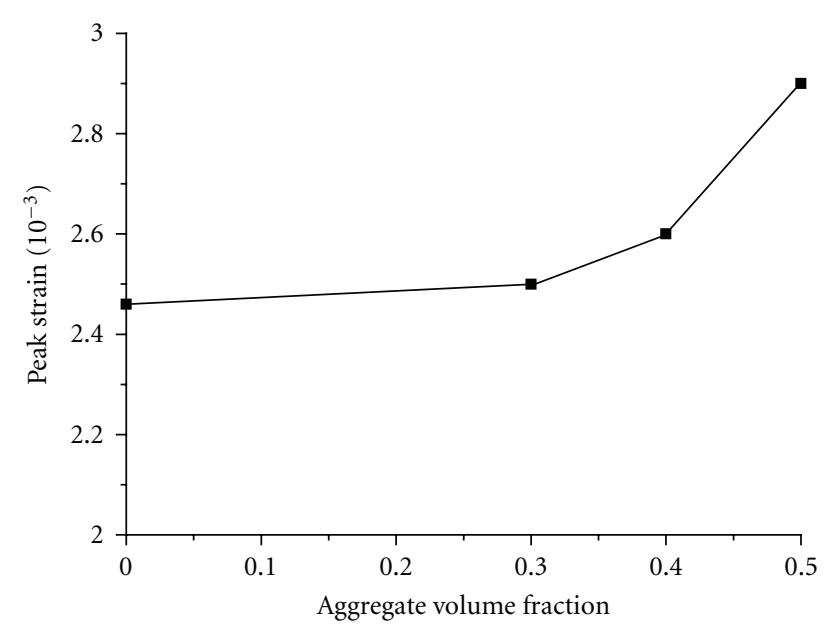

FIGURE 4: Peak strain of lightweight aggregate concrete with inorganic polymer binder.

lower strength of the lightweight aggregate than that of the concrete. The ratio of the cubic compressive strength $\left(f_{\mathrm{cu}}\right)$ to the prism compressive strength $\left(f_{c}\right)$ increases and tends to 1 . This is because the more the lightweight aggregate, the lower the strength of the lightweight aggregate concretes and the smaller the cyclo-hoop effect, resulting in fewer difference between the cubic and the prism compressive strengths.

3.3. Elastic Modulus. The elastic modulus $E_{c}$ of the lightweight aggregate concretes with inorganic polymer can be calculated by the following formula [11] based on the stressstrain curve:

$$
E_{c}=\frac{\sigma_{2}-\sigma_{1}}{\varepsilon_{2}-0.005 \%}
$$




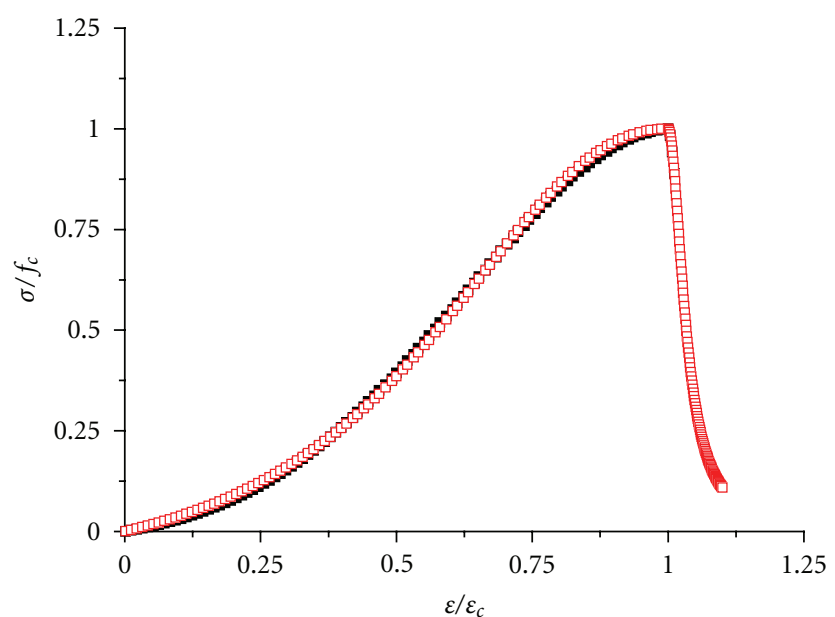

(a)

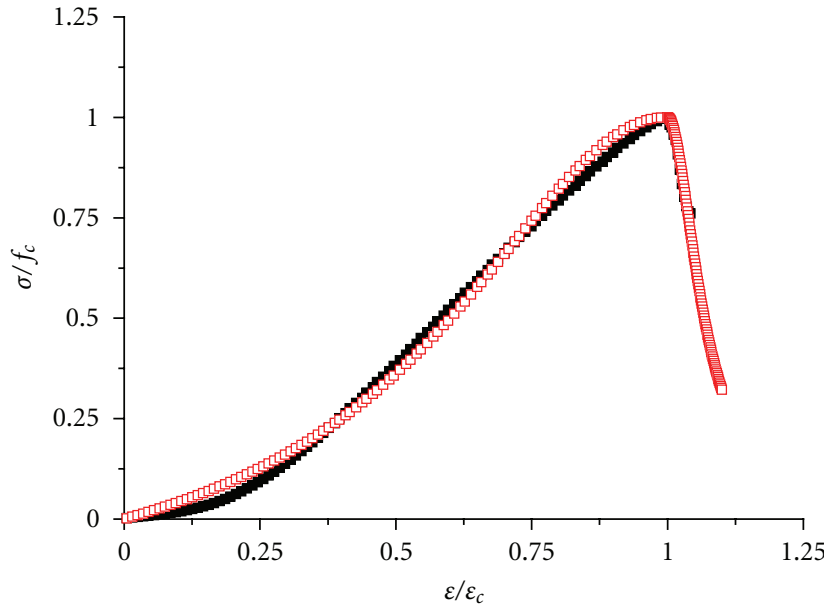

(b)

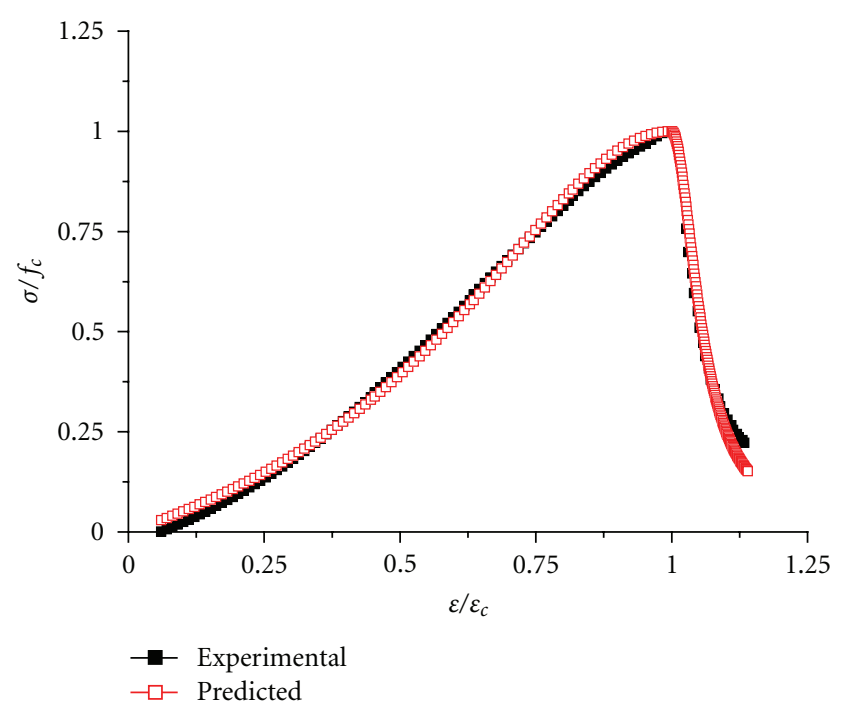

(c)

FIGURE 5: (a) Comparison of the predicted and experimental curves of concrete containing 30\% lightweight aggregate. (b) Comparison of the predicted and experimental curves of concrete containing $40 \%$ lightweight aggregate. (c) Comparison of the predicted and experimental curves of concrete containing 50\% lightweight aggregate.

where $\sigma_{1}$ is the stress corresponding to a strain of $0.005 \%$, $\sigma_{2}$ is the stress corresponding to the $40 \%$ of the peak load, $\sigma_{1}$ is the stress corresponding to a strain of $0.005 \%$, and $\varepsilon_{2}$ is the strain at the stress level $\sigma_{2}$, respectively. As shown in Figure 3, the elastic modulus of concretes with different volume fraction of lightweight aggregate decreased as the volume of lightweight aggregate increased. This is due to the elastic modulus of lightweight aggregate being lower than that of mortar.

3.4. Peak Strain. Figure 4 shows the peak strain of lightweight aggregate concrete with inorganic polymer binder. As shown in Figure 3, the peak strain of lightweight aggregate concrete increased as the volume fraction of lightweight aggregate increased. The main reason for the peak strain increase was that the elastic modulus of lightweight aggregate was lower than hardened inorganic polymer binder.

3.5. Prediction of Stress-Strain Relations. In this study, a model proposed by Ding et al. [12] is used to obtain an equation applicable to lightweight aggregate concrete with inorganic polymer binder. The expression is of the following form.

(1) Expression for the ascending branch $\left(\varepsilon / \varepsilon_{c} \leq 1\right)$

$$
\frac{\sigma}{f_{c}}=\frac{A\left(\varepsilon / \varepsilon_{c}\right)+(B-1)\left(\varepsilon / \varepsilon_{c}\right)^{2}}{1+(A-2)\left(\varepsilon / \varepsilon_{c}\right)+B\left(\varepsilon / \varepsilon_{c}\right)^{2}} .
$$

(2) Expression for the descending branch $\left(\varepsilon / \varepsilon_{c} \geq 1\right)$

$$
\frac{\sigma}{f_{c}}=\frac{\varepsilon / \varepsilon_{c}}{C\left(\varepsilon / \varepsilon_{c}-1\right)^{2}+\varepsilon / \varepsilon_{c}} .
$$


In (2) and (3), $A, B$, and $C$ are coefficients to be determined. The parameter $A$ is the ratio of elastic modulus and the peak secant modulus. The parameter $B$ is related to control the attenuation degree of the elastic modulus of ascending branch of the curve. The parameter $C$ is related to the ductility of the lightweight aggregate concrete with inorganic polymer binder. The larger the $B$-value is, the smaller is the ductility.

The parameter $A, B$, and $C$ were obtained from leastsquare fitting based on the stress-strain curves of concretes containing different volume fraction of lightweight aggregate; the values of $A, B$, and $C$ are given in Table 4 .

Three stress-strain curves of concretes containing 30\%, $40 \%$, and $50 \%$ volume fraction of lightweight aggregate, which take $\sigma / f_{c}$ and $\varepsilon / \varepsilon_{0}$ as dimensionless coordinates, are shown in Figures 5(a), 5(b), and 5(c), respectively.

A comparison of the curves for proposed model equation with the experimental stress-strain curves showed good agreement for concretes containing 30\%, 40\%, and 50\% volume fraction of lightweight aggregate.

\section{Conclusions}

(1) When the volume fraction of lightweight aggregate in the high-performance lightweight aggregate concrete based on inorganic polymer binder increased from 0 to $50 \%$, all the cubic compressive strength, prism compressive strength, and elastic modulus decreased, while the ratio value of $f_{c} / f_{\text {cu }}$ increased from 0.88 to 0.95 .

(2) The peak strain of concrete with inorganic polymer binder increases as the volume fraction of lightweight aggregate increased.

(3) The stress-strain curves of high-performance lightweight aggregate concrete based on inorganic polymer binder under uniaxial compressive loading can be fitted by cubic polynomial and rational fraction.

\section{Acknowledgment}

The authors acknowledge the financial supported by Hunan Provincial Innovation Foundation For Postgraduate (Grant no. CX2010B100).

\section{References}

[1] O. Kayali, "Fly ash lightweight aggregates in high performance concrete," Construction and Building Materials, vol. 22, no. 12, pp. 2393-2399, 2008.

[2] P. K. Mehta, "Greening of the concrete industry for sustainable development," Concrete International, vol. 24, no. 7, pp. 23-28, 2002.

[3] M. Sofi, J. S. J. van Deventer, P. A. Mendis, and G. C. Lukey, "Engineering properties of inorganic polymer concretes (IPCs)," Cement and Concrete Research, vol. 37, no. 2, pp. 251257, 2007.

[4] P. Duxson, A. Fernández-Jiménez, J. L. Provis, G. C. Lukey, A. Palomo, and J. S. J. Van Deventer, "Geopolymer technology: the current state of the art," Journal of Materials Science, vol. 42, no. 9, pp. 2917-2933, 2007.

[5] J. Davidovits, "Geopolymers - inorganic polymeric new materials," Journal of Thermal Analysis, vol. 37, no. 8, pp. 1633-1656, 1991.

[6] F. G. Collins and J. G. Sanjayan, "Workability and mechanical properties of alkali activated slag concrete," Cement and Concrete Research, vol. 29, no. 3, pp. 455-458, 1999.

[7] J. Temuujin and A. van Riessen, "Effect of fly ash preliminary calcination on the properties of geopolymer," Journal of Hazardous Materials, vol. 164, no. 2-3, pp. 634-639, 2009.

[8] J. Tailby and K. J. D. MacKenzie, "Structure and mechanical properties of aluminosilicate geopolymer composites with portland cement and its constituent minerals," Cement and Concrete Research, vol. 40, no. 5, pp. 787-794, 2010.

[9] J. A. Rossignolo and M. V. C. Agnesini, "Mechanical properties of polymer-modified lightweight aggregate concrete," Cement and Concrete Research, vol. 32, no. 3, pp. 329-334, 2002.

[10] Y. Ke, A. L. Beaucour, S. Ortola, H. Dumontet, and R. Cabrillac, "Influence of volume fraction and characteristics of lightweight aggregates on the mechanical properties of concrete," Construction and Building Materials, vol. 23, no. 8, pp. 2821-2828, 2009.

[11] J. Xiao, J. Li, and C. Zhang, "Mechanical properties of recycled aggregate concrete under uniaxial loading," Cement and Concrete Research, vol. 35, no. 6, pp. 1187-1194, 2005.

[12] F. X. Ding, X. Y. Ying, and Z. W. Yu, "Unified calculation method of uniaxial mechanical properties of lightweight aggregate concrete," Journal of Central South University, vol. 41, no. 5, pp. 1973-1979, 2010 (Chinese). 

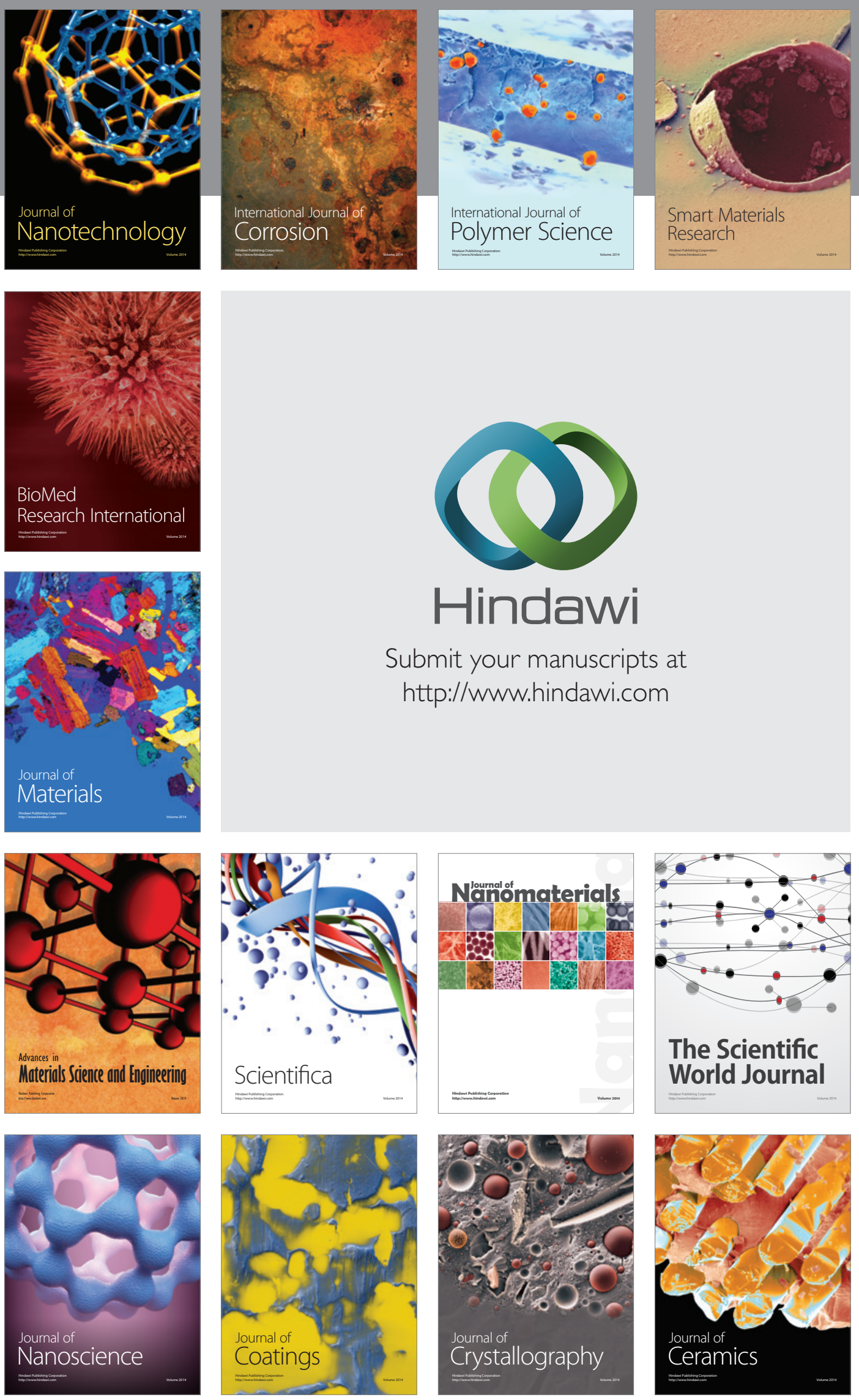

The Scientific World Journal

Submit your manuscripts at

http://www.hindawi.com

\section{World Journal}

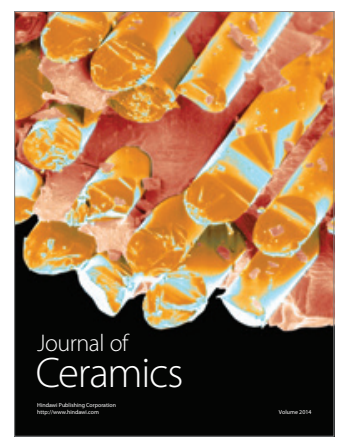

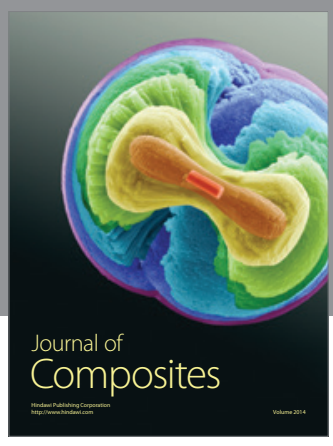
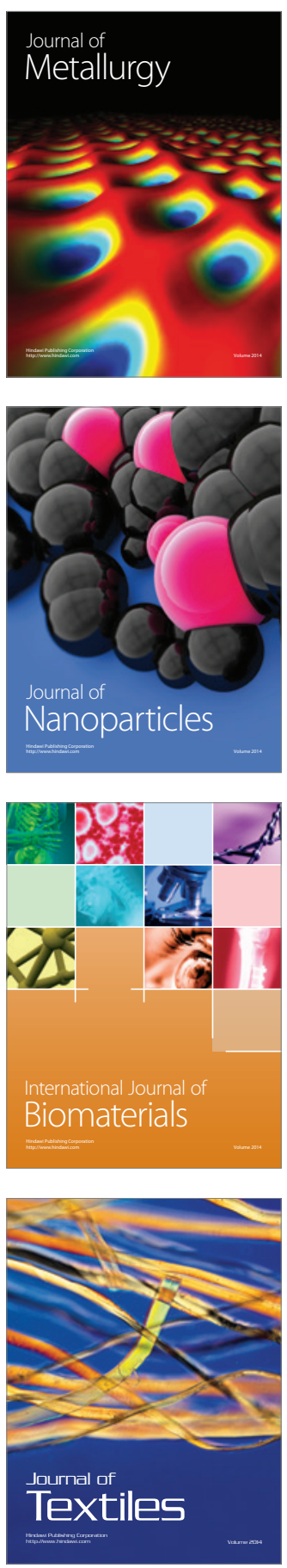